\title{
Coagulase-negative strains of staphylococcus possessing antigen 51 as agents of urinary infection
}

\author{
A. TORRES PEREIRA \\ From the Instituto Bacteriológico Câmara Pestana, University of Lisbon, Portugal
}

SYNOPSIS A group of strains of Staphylococcus albus is described which produced neither coagulase nor haemolysin, was slightly sensitive or resistant to novobiocin, and sensitive to all other anti- $N$ biotics, to sulphonamides, and to nitrofurantoin. The agglutinating antigen 51 was isolated fromo all strains from patients with urinary infections and abundant pyuria.

In more than 40 cases studied it was not possible to isolate any other bacterial agent, and the 3 cure of clinical symptoms always coincided with the disappearance of the coagulase-negative staphylococcus strain.

Coagulase-negative strains of Staphylococcus albus are usually regarded as contaminants and are not considered potentially pathogenic. There are, however, certain cases described in the literature which can be regarded as showing the pathogenicity of this organism (e.g., Matthew, 1951; O'Hare and Stevenson, 1953; Smith, Beals, Kingsbury, and Hasenclever, 1958; Resnekov, 1959; Brandt and Swahn, 1960; Callaghan, Cohen, and Stewart, 1961; Cohen and Callaghan, 1961). Veterinary surgeons (e.g., Thörne, $1957 \mathrm{a}$ and 1957b) have also found these strains in a number of cases.

In recent years, many patients with urinary infection and intense pyuria have been observed, and in all of them a pure growth of a strain of Staphylococcus albus with particular biological characteristics was isolated.

\section{METHODS}

EXAMINATION OF THE URINE The deposit of the centrifuged urine was examined in the fresh state by direct microscopical examination, using the Gram and ZiehlNeelsen methods, and by culture on Endo and blood-agar plates.

BIOCHEMICAL STUDY OF THE STRAIN The simultaneous production of coagulase and haemolysin was investigated using the Joiris (1952) technique. The egg-yolk reaction was studied using the technique of Gillespie and Alder (1952).

Received for publication 23 January 1962.
ANTIBIOTIC SENSITIVITY TESTS The following antibioticsO were tested:-Penicillin, streptomycin, erythromycin, chloramphenicol, the tetracyclines, novobiocin, nitro-o furantoin, and the sulphonamides (sulphasoxazole, sulphamethoxypyridazine, and sulphamethylthiadiazole) The low and medium-concentration Difco sensitivity discs and Oxoid multodisks of two concentrations were used. The concentrations of novobiocin were 5 and $10 \mu \mathrm{g}$ (Difco) and 5 and $30 \mu \mathrm{g}$. (Oxo).

SEROLOGICAL TECHNIQUE The serological technique pre viously described (Torres Pereira, 1960, 1961) was adopted.

Serum 51 was taken to be absorbed when it agglutinated only strain 51 (reference strain 51877, a coagulase윽 negative strain of staphylococcus isolated from urine) and not any other of the 23 standard strains of the author's basic set.

\section{RESULTS}

Using the material described in previous work (Torres Pereira and Carvalho Araújo, 1961), and adding to it new cases of urinary infection, we cong cluded that in Portugal the percentage of urinar 6 infections due to Staphylococcus (aureus and albus) iई్ about $9 \%$, there being a slight predominance of Staphylococcus aureus (57\% of the staphylococcato infections) over Staphylococcus albus (43\%) in $\overline{+}$ fections.

Forty cases of urinary infection caused b Staphylococcus albus were studied. The subjects wer almost entirely women. Direct examination of the् 
deposit showed many pus cells and staphylococci. No acid-fast bacilli or other bacteria were noted and guinea-pig inoculation, performed in over $50 \%$ of the cases, was always negative. Cultures yielded a pure growth of Staphylococcus albus. The pigment was sometimes unmistakably white and sometimes yellow; in the majority of cases, however, the classification of this pigment became difficult after 48 hours. None of the strains produced coagulase or haemolysin, and the egg-yolk reaction was always negative. All strains proved resistant or only slightly sensitive to novobiocin and sensitive to the other antibacterial agents tested.

From the serological point of view, remarkable homogeneity was noted. Thus, a serum prepared with strain 51877 isolated from a patient with urinary infection and absorbed with standard strain 18 , produced a powerful specific serum capable of agglutinating all strains isolated from urinary infections. This specific serum, which is absorbed in relation to all the strains of Staphylococcus aureus that constitute the standard basic set, is called serum 51 since it does not correspond to any of the 50 original standard strains (Torres Pereira, 1960). The agglutination tests generally showed very strong reactions but in some cases they were difficult to interpret because some strains seemed to be spontaneously agglutinable.

Seventeen of these strains were sent to Professor R. E. O. Williams and to Dr. M. Patricia Jevons. All of them proved to be untypable with the phages of the international typing set used at routine test dilution. With phages used at $\times 1,000$ the routine test dilution three strains showed some lysis $(3 \mathrm{~A} / 3 \mathrm{~B}$; 47A; 6/7/47), and another showed inhibition reactions with phage 55 . Taken as a whole, these almost entirely negative tests reinforced the view that the group was homogeneous.

\section{DISCUSSION}

It is usual to regard non-coagulase producing Staphylococcus albus as non-pathogenic, and generally speaking, these strains are regarded as accidental contaminants of urine. Nevertheless, my observations taken as a whole led me to believe that in certain cases coagulase-negative staphylococci may be pathogenic. In all the cases studied clinical and bacteriological cure coincided perfectly.

There is sometimes a tendency to believe that certain groups of bacteria give rise to specific clinical pictures although such associations have not been satisfactorily explained. For example, the staphylococci responsible for boils in hospital epidemics are normally of phage group I (especially phage type $80 / 81$ ); impetigo is very commonly caused by group II staphylococci (especially phage type 71); and cases of food poisoning are caused by group III staphylococci.

Two other examples can be mentioned: the peculiar pathogenicity of group A streptococci type 39 (Wahl, Cayeux, and Derlot, 1960) and the glomerulonephritis due to type 12 streptococci (Rammelkamp and Weaver, 1953; Reed and Matheson, 1954).

Other localizations were investigated of coagulasenegative staphylococcus strains having antigen 51 and being slightly sensitive or resistant to novobiocin. Of 70 strains of Staphylococcus albus isolated from the nose, only one proved to be resistant to novobiocin, whereas 30 other strains isolated from the skin of healthy subjects proved to be, without exception, sensitive to novobiocin and were not agglutinated by serum 51 .

The antigenic structure and the sensitivity to novobiocin of coagulase-negative strains of Staphylococcus albus isolated from staphylococcal bacterial endocarditis as a complication of mitral valvotomy (described by several authors) are not known.

A set of 17 coagulase-negative strains of staphylococcus of bovine origin was received from $\mathrm{H}$. Thörne (Sweden). Many of these strains proved to be spontaneously agglutinable. Most were slightly sensitive or resistant to novobiocin and slightly sensitive also to penicillin. None of them contained antigen 51 .

I wish to thank Professor R. E. O. Williams and Dr. M. Patricia Jevons, of the Streptococcus and Staphylococcus Reference Laboratory, Colindale, London, for carrying out the phage typing, and Dr. H. Thörne, of Veterinärbakt. Laboratoriet, Västeras, Sweden, for supplying the strains of bovine origin.

\section{REFERENCES}

Brandt, L., and Swahn, B. (1960). Acta med. scand., 166, 125.

Callaghan, R. P., Cohen, S. J., and Stewart, G. T. (1961). Brit. med. J., $1,860$.

Cohen, S. J., and Callaghan, R. P. (1961). Ibid., 2, 677.

Gillespie, W. A., and Alder, V. G. (1952). J. Path. Bact., 64. 187.

Joiris, E. (1952). Rev. belge Path., 22, 189.

Matthew, H. (1951). Lancet, 1, 146.

O'Hare, M. M., and Stevenson, J. S. (1953). Brit. med. J., 2, 1086.

Rammelkamp, C. H., and Weaver, R. S. (1953). J. clin. Invest., 32, 345.

Reed, R. W., and Matheson, B. H. (1954). J. infect. Dis., 95, 191 and 202.

Resnekov, L. (1959). Lancet, 2, 597.

Smith, I. M., Beals, P. D., Kingsbury, K. R., and Hasenclever, H. F. (1958). A.M.A. Arch. intern. Med., 102, 375.

Thörne, H. (1957a). Nord. Vet. Med., 9, 34.

- (1957b). Ibid., 9, 763.

Torres Pereira, A. (1960). Arq. Inst. Bact. Câm. Pest., 10, 549.

- (1961). J. Path. Bact., 81, 151.

- and Carvalho Araújo, F. (1961), Bol. Clin. H. C. L., 25, 111.

Wahl, R., Cayeux, P.. and Derlot, E. (1960). Ann. Inst. Pasteur., 99, 654. 